\title{
Quantifying unsteadiness and dynamics of pulsatory volcanic activity
}

\author{
L. Dominguez $^{\text {a }, *}$, L. Pioli ${ }^{\text {a }}$, C. Bonadonna ${ }^{a}$, C.B. Connor ${ }^{b}$, D. Andronico ${ }^{c}$, A.J.L. Harris ${ }^{d}$, \\ M. Ripepe ${ }^{\mathrm{e}}$
}

a Département des sciences de la Terre, Université de Genève, Switzerland

${ }^{\mathrm{b}}$ Departement of Geology, University of South Florida, USA

c Istituto Nazionale di Geofisica e Vulcanologia Sezione di Catania, Italy

d Laboratoire Magmas et Volcans, Université Blaise Pascal, France

e Dipartamento Scienze della Terra, Università degli Studi di Firenze, Italy

\section{A R T I C L E I N F O}

\section{Article history:}

Received 29 February 2016

Received in revised form 28 March 2016

Accepted 29 March 2016

Available online $\mathrm{xxxx}$

Editor: T.A. Mather

\section{Keywords:}

\section{explosions}

pulsatory activity

magma viscosity

repose interval

source dynamics

eruptive style

\begin{abstract}
A B S T R A C T
Pulsatory eruptions are marked by a sequence of explosions which can be separated by time intervals ranging from a few seconds to several hours. The quantification of the periodicities associated with these eruptions is essential not only for the comprehension of the mechanisms controlling explosivity, but also for classification purposes. We focus on the dynamics of pulsatory activity and quantify unsteadiness based on the distribution of the repose time intervals between single explosive events in relation to magma properties and eruptive styles. A broad range of pulsatory eruption styles are considered, including Strombolian, violent Strombolian and Vulcanian explosions. We find a general relationship between the median of the observed repose times in eruptive sequences and the viscosity of magma given by $\eta \approx 100 \cdot t_{\text {median }}$. This relationship applies to the complete range of magma viscosities considered in our study ( $10^{2}$ to $10^{9} \mathrm{Pas}$ ) regardless of the eruption length, eruptive style and associated plume heights, suggesting that viscosity is the main magma property controlling eruption periodicity. Furthermore, the analysis of the explosive sequences in terms of failure time through statistical survival analysis provides further information: dynamics of pulsatory activity can be successfully described in terms of frequency and regularity of the explosions, quantified based on the log-logistic distribution. A linear relationship is identified between the log-logistic parameters, $\mu$ and $s$. This relationship is useful for quantifying differences among eruptive styles from very frequent and regular mafic events (Strombolian activity) to more sporadic and irregular Vulcanian explosions in silicic systems. The time scale controlled by the parameter $\mu$, as a function of the median of the distribution, can be therefore correlated with the viscosity of magmas; while the complexity of the erupting system, including magma rise rate, degassing and fragmentation efficiency, can be also described based on the log-logistic parameter $s$, which is found to increase from regular mafic systems to highly variable silicic systems. These results suggest that the periodicity of explosions, quantified in terms of the distribution of repose times, can give fundamental information about the system dynamics and change regularly across eruptive styles (i.e., Strombolian to Vulcanian), allowing for direct comparison and quantification of different types of pulsatory activity during these eruptions.
\end{abstract}

(c) 2016 Elsevier B.V. All rights reserved.

\section{Introduction}

Unsteady, pulsatory dynamics is typical of relatively low energy volcanic eruptions in which the eruptive event consists of a sequence of explosions of similar intensity. Pulsatory eruptive activity is considered as typical of Strombolian and Vulcanian activity (e.g. MacDonald, 1972), but may also occur in other types

\footnotetext{
* Corresponding author.

E-mail address: Lucia.Dominguez@unige.ch (L. Dominguez).
}

of eruptions. Spacing and intensity of explosions can significantly affect the eruptive dynamics. In fact, very closely spaced explosions might originate as unsteady jets, but generate steady plumes, whereas low-frequency explosions might result in discrete explosive plumes (Valentine and Gregg, 2008; Chojnicki et al., 2015; Fig. 1). For this reason, the variability of intensity and frequency of explosive pulses results in eruption complexity, which is characteristic of Strombolian, violent Strombolian (typically associated to mafic eruptions) and Vulcanian eruptions (typically associated to silicic eruptions). However, such variability can also characterise other eruptive styles, such as Hawaiian or Surtseyan eruptions. 
Table 1

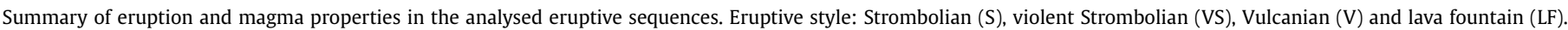

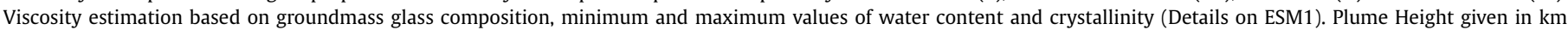

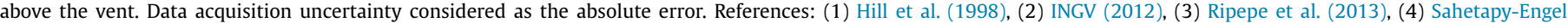

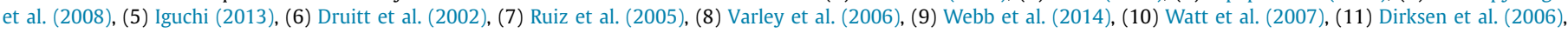
(12) Valade et al. (2012), (13) Ripepe et al. (2008).

\begin{tabular}{|c|c|c|c|c|c|c|c|}
\hline Dataset & Composition & $\begin{array}{l}\text { Viscosity } \eta \\
\text { (log Pa s) } \\
\text { (range) }\end{array}$ & $\begin{array}{l}\text { Plume height } \\
\text { (km) (Ref.) }\end{array}$ & $\begin{array}{l}\text { Median of } \\
\text { repose intervals } \\
(\mathrm{s})\end{array}$ & $\begin{array}{l}\text { Median } \\
\text { uncertainty } \\
\text { (s) }\end{array}$ & $\begin{array}{l}\text { Standard } \\
\text { deviation } \\
\text { (s) }\end{array}$ & Style \\
\hline Etna (Et-Ju) (07.29.2012) & Basalt & $2.04(1.53-2.56)$ & - & 2.4 & 1 & 0.8 & $\mathrm{~S}$ \\
\hline Cerro Negro (CN) (11.30.1995) & Basalt & $3.10(2.22-3.99)$ & $0.1-0.8(1)$ & 7.2 & 2 & 3.5 & VS \\
\hline Etna (Et-Ap) (04.12.2012) & Basalt & $2.28(1.70-2.85)$ & $0.1-3.0(2)$ & 1.6 & 3 & 1.0 & LF \\
\hline Eyjafjallajökull (Eyj) (05.04.2010) & Andesite & $4.26(3.99-4.52)$ & $0.4-7.0(3)$ & 25.0 & 1 & 21.7 & $\mathrm{~V}$ \\
\hline Santiaguito (Stg) (08-12.01.2003) & Dacite & $6.84(4.99-8.70)$ & $1.0-4.0(4)$ & 1148.3 & 1 & 1454.4 & $\mathrm{~V}$ \\
\hline Sakurajima (Skj-Sh) (01.09.2011-2.01.2003) & Andesite & $6.56(5.09-8.02)$ & $0.4-2.5(5)$ & 6840.0 & 50 & 28784.3 & $\mathrm{~V}$ \\
\hline Sakurajima (Skj-M) (09.05.1977-27.09.1978) & Andesite & $7.37(5.73-9.01)$ & - & 43710.0 & 20 & 150388.3 & $\mathrm{~V}$ \\
\hline Soufrière Hills (SH) (21.09.1997-21.10.1997) & Andesite & $7.74(6.35-9.13)$ & $0.4-15.2(6)$ & 33240.0 & 20 & 17430.8 & $\mathrm{~V}$ \\
\hline \multicolumn{8}{|l|}{$\underline{\text { Published Data }}$} \\
\hline Anak Krakatau (AK) (12-13.01.1960) & Andesite & $4.31(3.40-5.22)$ & - & $124.0(10)$ & - & 7980 & $\mathrm{~V}$ \\
\hline Stromboli (Str) & Basalt & $4.33(3.65-5.04)$ & $0.05-0.4(13)$ & $270.0(13)$ & - & - & $\mathrm{S}$ \\
\hline Kameni Island (KI) (22-23.02.1926) & Andesite & $4.80(3.89-5.69)$ & - & $214.8(10)$ & - & - & $\mathrm{V}$ \\
\hline Tungurahua (Tgh) (2004) & Andesite & $4.81(4.07-5.55)$ & $0.1-3.0(7)$ & $764.4(8)$ & - & - & $\mathrm{V}$ \\
\hline Arenal (Are) (10-22.02.2005) & Andesite & $4.99(3.90-6.10)$ & $1.0-3.0(12)$ & $1800.0(12)$ & - & - & $\mathrm{V}$ \\
\hline Colima (Col) (May 2002) & Andesite & $5.33(4.20-6.47)$ & $0.6-1.6(9)$ & $308.3(8)$ & - & 765 & $\mathrm{~V}$ \\
\hline Shiveluch (Svl) (4 Jan 2002-30.11.2003) & Andesite & $6.83(4.82-8.83)$ & $1.0-11.0(11)$ & $24444.0(11)$ & - & - & $\mathrm{V}$ \\
\hline
\end{tabular}
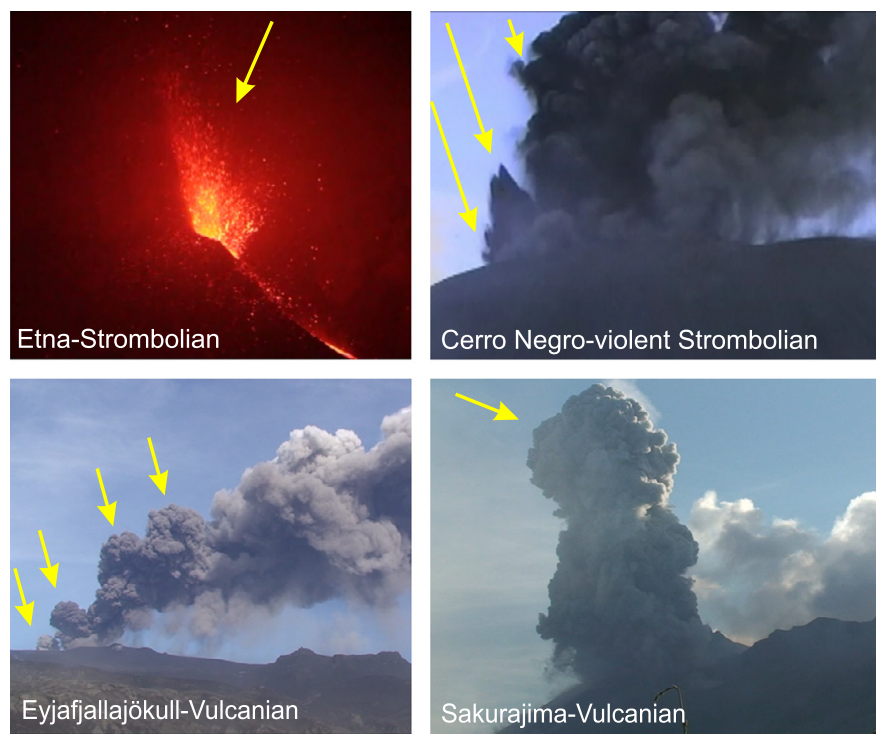

Fig. 1. Photographs showing type explosions from eruptions selected in the dataset. Cerro Negro picture is an instantaneous from the video, while Etna picture was taken by D. Andronico, Eyjafjallajökull by C. Bonadonna and Sakurajima by L. Dominguez.

Unfortunately, this complexity is not encompassed by current classification schemes as they are mostly based on deposit properties, e.g. tephra dispersal, grainsize and/or erupted volume, with the assumption of steady-state conditions (e.g. MacDonald, 1972; Walker, 1973; Pyle, 1989). Pulsatory volcanic activity has been also studied in terms of fluid and source dynamics at specific volcanoes (Mason et al., 2006; Sahetapy-Engel et al., 2008; Marchetti et al., 2009; Gonnermann and Manga, 2012; Moitra et al., 2013). In the context of these studies, it is important to quantify unsteadiness and relate it to traditional eruptive styles. In addition, the unsteady behaviour of explosive eruptions cannot be defined based only on the stratigraphic record. For example, it is difficult to constrain closelyspaced single Strombolian or Vulcanian events from a stratified fallout deposit, and no information about the timescale of explosive pulses can be derived from individual tephra layers. Moreover, many small explosions of similar magnitude can generate massive deposits, making it difficult even to identify the discontin- uous behaviour of the eruptions. For these reasons, classification schemes that are only based on deposit features cannot well describe the complexities of unsteady activity and are difficult to apply to small-moderate eruptions that are typically characterised by a large variability of intensity and frequency of explosive pulses (Bonadonna et al., 2014). The quantification of the pulsatory behaviour of these eruptions is fundamental not only for the understanding and classification of eruptive styles, but also for hazard assessment, especially in the case of long lasting eruptions.

This study compares different pulsatory eruptions of variable eruptive style (i.e. efficiency of fragmentation, intensity and variability of pulses) based on the distribution of repose time between pulses. Here, pulsatory explosive activity is considered as a stochastic renewal process (Marzocchi and Bebbington, 2012) and is studied based on the statistical analysis of the duration of repose times (i.e. failure time sensu stricto, Cox and Oakes, 1984). Repose time $(t)$ is defined as the time interval elapsed between the onsets of two consecutive explosive events, which we use to determine the distribution and frequency of explosions. In general, mafic magmas display eruptions with frequent pulses $\left(10^{-1}-10^{2} \mathrm{~s}\right.$; Table 1), while intermediate and silicic magmas have less frequent pulses $\left(10^{2}-10^{5} \mathrm{~s}\right.$; Table 1$)$. An explosive event (i.e. explosion) indicates one single explosive pulse, while an eruption indicates an explosive sequence comprising several to thousands of explosive events. In any case, open vent conditions (i.e. active vent outgassing during long repose times) characterise the entire explosive sequence. We associate each pulse to a magma fragmentation event (failure), but our study does not imply any failure mechanics model (e.g. Voight, 1988).

A systematic statistical approach is necessary to quantitatively describe the variability and distribution of explosions, despite significant differences in the timescales of this activity at different volcanoes (repose time between explosions ranging from seconds to few days). Statistical models are commonly applied to study the distribution of repose times either between eruptions (e.g. Pyle, 1998; Dzierma and Wehrmann, 2010; Marzocchi and Bebbington, 2012) or between Vulcanian explosions (Connor et al., 2003; Varley et al., 2006; Watt et al., 2007).

Consequently, we analyse sequences of explosions of variable intensity and explosivity (Strombolian, violent Strombolian and Vulcanian), to $i$ ) examine the basic descriptive statistical param- 
eters of the distribution of explosions and correlate them with magma properties, $i i)$ perform a detailed statistical analysis on selected datasets by fitting specific distributions to the repose times, and iii) compare the main distribution parameters of the eruptions for a more precise description of the variability and characteristics of pulsatory explosive styles.

\section{Datasets}

Eruptive sequences were analysed based on the general properties of the repose-time distribution and eruption characteristics already published by previous authors (Table 1). Among them, original data from 8 explosive sequences that occurred at 6 volcanoes were analysed in detail. Specific information on the original explosive sequences is provided in the following sections.

\subsection{Mount Etna volcano (Italy)}

Mount Etna is an active volcano characterised by persistent and frequent effusive and explosive activity with open vent outgassing conditions and high initial magma volatile content (Spilliaert et al., 2006). Recently, summit activity has occurred at five distinct cones, known as the Northeast crater (NEC), the Voragine and Bocca Nuova, the Southeast crater (SEC) and the younger New Southeast crater (NSEC). Between 2011 and 2015 all eruptive activity at NSEC consisted of brief episodes of vigorous lava fountaining (approx. 50 episodes), known as "paroxysms", and some Strombolian activity (Andronico et al., 2014).

\subsubsection{Eruption of 29 July 2012 (Et-Ju)}

Intermittent Strombolian activity started on 2 July 2012 at the Bocca Nuova crater and persisted until the end of August 2012 (Ciancitto et al., 2012). The time series for this explosive sequence consists of regular Strombolian explosions with repose intervals ranging from 0.16 to $7 \mathrm{~s}$, derived from around $28 \mathrm{~min}$ of video footage recorded on 30 July 2012.

\subsubsection{Eruption on 12 April 2012 (Et-Ap)}

Since 10 April 2012, Strombolian explosions were reported at the NSEC by the INGV (2012). On 12 April, a second vent opened at 15:42 (local time) with predominantly Strombolian activity and emission of poor-fed lava flows. During this period both vents were the locus of mixed activity, including minor Strombolian explosions and lava fountains producing ash plumes up to $3 \mathrm{~km}$ above sea level (a.s.l.). Around 17:15 the paroxysmal phase stopped while lava flows, no longer fed, continued to move towards the Valle del Bove (INGV, 2012). Around $40 \mathrm{~min}$ of video footage was analysed, with observed repose intervals ranging from 0.12 to $5.76 \mathrm{~s}$.

\subsection{Cerro Negro volcano, Nicaragua (CN)}

Cerro Negro is a basaltic volcano characterised by volatilerich magmas producing eruptions of different magnitude since it started its activity in 1850 (Roggensack et al., 1997; Hill et al., 1998). The 1995 eruption started on 24 May and increased in frequency and intensity with time, producing phreatic explosions and plumes between 100 and $1000 \mathrm{~m}$ above the vent. Activity declined to cessation on 9-16 August 1995. The last phase of this eruption started on 19 November 1995 with low energy Strombolian explosions constructing a small cinder cone within the 1992 crater, accompanied by lava flows to the North. From 28 November to 2 December 1995, the explosive activity increased, forming a volcanic cloud dispersed to the $\mathrm{W}$ and $\mathrm{SW}$, fed by explosions spaced between 2 and $7 \mathrm{~s}$. The plume reached a maximum height of $810 \pm 20 \mathrm{~m}$ above the vent on 1 December 1995. From 2 to 6 December 1995, small explosions marked the end of the eruption, with a final burst after 26 hrs hiatus (Hill et al., 1998). A sequence of $50 \mathrm{~min}$ of video footage recorded on 30 November 1995 was analysed showing a sequence of Strombolian to violent Strombolian explosions whose repose interval ranged from 0.33 to $22 \mathrm{~s}$.

\subsection{Eyjafjallajökull, Iceland (Eyj)}

Eyjafjallajökull is a small-volume basaltic volcano whose last eruption started on 14 April 2010 at the main summit and lasted 39 days (14 April-22 May). Four main eruption phases were identified and well documented (e.g. Gudmundsson et al., 2012). In this study, we analysed about 100 minutes of thermal images from the 4 May, during the beginning of the second explosive phase, with explosions occurring with repose intervals ranging from 1 to $105 \mathrm{~s}$. Thermal image analysis for this period shows that the plume was sustained by a series of thermal puffs of hot gases and ash, occurring at a mean period of around $30 \mathrm{~s}$, and reaching heights up to $2 \mathrm{~km}$ a.s.l. (Ripepe et al., 2013).

\subsection{Santiaguito, Guatemala (Stg)}

Santiaguito, considered to be one of the most active volcanoes in Central America during the last 150 yrs (Rose, 1972), is a dacitic dome complex formed by 4 vents (i.e. "El Caliente", "La Mitad", "El Monje" and "El Brujo"). During 2003, its activity was characterised by weak Vulcanian explosions associated with low but continuous degassing with magma eruption rates up to $2-3 \mathrm{~kg} \mathrm{~s}^{-1}$ (Harris et al., 2003). In this study, 84 explosions with repose intervals ranging from $110 \mathrm{~s}$ to about 2 hrs were extracted from the coupled records of a thermal-acoustic-seismic array deployed in January 2003 by Sahetapy-Engel et al. (2008), who described the explosions as thermal emissions related to shear-induced fragmentation due to a stick-slip flow regime. These emissions had durations of 1 to $8 \mathrm{~min}$ and repose periods of 1 to $56 \mathrm{~min}$.

\subsection{Sakurajima, Japan}

Sakurajima is the most active volcano in Japan. It is characterised by intermittent explosions first recorded at Minamidake crater (7.900 Vulcanian explosions from 1955 to 2005, Iguchi, 2013); and then gradually shifting to Showa crater with an initial phreatic period (2006-2007), followed by Vulcanian explosions starting on the 3 February 2008 to the present. The annual frequency in 2010-2011 was almost double that of older Minamidake activity, but the explosions had intensities 1 to 2 orders of magnitude smaller (Iguchi, 2013). Two sequences of Vulcanian explosions have been analysed: $i$ ) the explosions between May 1973 and April 1979 at Minamidake crater, represented by a dataset of 434 explosions between 9 May 1977 to 27 September 1978, with repose intervals ranging from $4 \mathrm{~min}$ to 12 days (i.e. Skj-M dataset); and ii) the explosions from 1 September 2011 to 2 January 2012 at Showa crater, with repose intervals from 2 min to around 2 days (i.e. Skj-Sh dataset).

\subsection{Soufrière Hills, Montserrat (SH)}

Explosive activity at Soufrière Hills volcano started in 1995 and is still ongoing. Activity during 1997 was characterised by 2 regular cycles of Vulcanian explosions in August and SeptemberOctober. In this study we have considered the consecutive period of 74 Vulcanian explosions that occurred in September-October extracted from seismic data and observations (Druitt et al., 2002), which have been previously analysed by Connor et al. (2003) and Watt et al. (2007). This activity is characterised by cyclic patterns of seismicity and conduit deformation accompanied by Vulcanian explosions, dome extrusion, dome collapses and ash-venting (Pyle, 
Table 2

Summary of the specific characteristics of the eruption studied. $n=$ number of explosions analysed. Range values are the shortest and longest repose times. Sakurajima-Showa dataset based on acoustic data, compiled from http:// www.data.jma.go.jp/svd/vois/data/tokyo/eng/volcano-activity/monthly.htm. Soufrière Hills dataset based on seismic data, from Druitt et al. (2002).

\begin{tabular}{llrl}
\hline Volcano & Dataset & $n$ & $\begin{array}{l}\text { Range } \\
(\mathrm{s})\end{array}$ \\
\hline Etna (Italy) & & & \\
Bocca Nuova crater & Et-Ju & 343 & $0.16-5.60$ \\
NSEC crater & Et-Ap & 442 & $0.12-5.76$ \\
Cerro Negro (Nicaragua) & CN & 371 & $0.33-21.85$ \\
Eyjafjallajökull (Iceland) & Eyj & 91 & $4-105$ \\
Santiaguito (Guatemala) & Stg & 84 & $110-6.39 \mathrm{e} 3$ \\
Sakurajima (Japan) & & & \\
Showa crater & Skj-Sh & 545 & $120-1.95 \mathrm{e} 5$ \\
Minamidake crater & Skj-M & 434 & $240-1.06 \mathrm{e} 6$ \\
Soufrière Hills (Montserrat) & SH & 74 & $8.8 \mathrm{e}-1.21 \mathrm{e} 5$ \\
\hline
\end{tabular}

1998; Druitt et al., 2002). In particular, the September-October Vulcanian cycle, characterised by explosion intervals of 2.5 to 34 hrs, was initiated by magma decompression induced by a large dome collapse.

\section{Methods}

\subsection{Original data acquisition}

Explosive pulses were identified either as distinct eruptive jets in visual records of the eruptions, with analysis of individual frames or as significant peaks in geophysical monitoring records (i.e. seismic, thermal, and/or acoustic signals). The error associated with estimating the repose interval data using different data acquisition strategies was quantified by considering $i$ ) the sampling rate of the instrumentation employed (i.e. the sampling frequency of geophysical signals and frames per second of digital videos), ii) the error associated with the identification of the onset time of recorded events (i.e. aleatory uncertainties), which is considerably larger for explosive events whose duration is of the same order of magnitude of the repose time (i.e. violent Strombolian and Lava Fountain activity); and iii) the error associated with the statistical analysis quantified as the standard error of each fitted parameter. All these sources account for an absolute error on the estimation of the repose intervals ranging from $1 \mathrm{~s}$ to $1 \mathrm{~min}$ resulting in an increasing accuracy of the measured intervals for longer lasting eruptions (i.e. hours to days, Table 1 and 2).

\subsection{Magma viscosity}

Groundmass glass composition and crystal content in pumice and scoria were considered as representative of melt composition and its crystallinity, respectively. Viscosity of the melt was calculated at the eruptive temperatures, either derived from direct measurement or petrology constraints. To take into account the uncertainty in the quantification of the dissolved water content, a maximum viscosity was calculated for degassed melt (i.e. with 0.5 wt.\% dissolved water) and a minimum viscosity for undegassed melts (i.e. with the maximum dissolved water as measured in melt inclusions). Melt viscosity was calculated following Giordano et al. (2008) and the effect of crystals on magma viscosity was accounted based on the model of Costa et al. (2009).

\subsection{Survival analysis}

Different statistical models can be applied to describe the distribution in time of the repose interval through survival analysis. Survival analysis of the repose interval is a univariate statistical technique that associates a single response, time to failure, to many explanatory variables (Cox and Oakes, 1984) and allows for the direct comparison of complex system responses resulting from the interaction of several physical processes.

The models used in this study apply only to stationary and independent time series whose probability distribution is constant in time. Stationarity of the repose interval was assessed for each eruptive sequence based on a moving-average test that provides a smoothed curve around the mean $\pm 1 \sigma$ limits and highlights the trends present in the dataset. It is important to highlight that within each sequence, consecutiveness and stationary conditions were tested in order to ensure homogeneous eruptive style; in the case these conditions were not met for the entire raw sequence, the statistical analysis was performed on stationary and consecutive time windows (i.e. datasets). Specific tests were performed on each dataset to determine if consecutive pulses are independent of what occurred before, a feature known as the lack of "memory of the system" or independence property. This property can be tested by calculating the correlation coefficient $(R)$ between successive repose intervals, visualised in a correlation scatter plot or lag correlation plot. This is a relatively simple method, applicable only to stationary datasets, which consists of comparing an identical copy of data that has been displaced by a fixed time. For example, given a dataset $T_{1}, T_{2}, \ldots, T_{n}$; and a lag $=1$, one can plot $T_{i} v s T_{i+1}$ for all $i$. If no time correlation exists between repose intervals, the correlation coefficient equals zero or fluctuates around zero, otherwise, correlation coefficients will be larger than confident limits, usually estimated as the mean $\pm 2 \sigma$ (Cox and Lewis, 1966).

Each distribution can be expressed in terms of a Probability Density Function (PDF), $f_{T}(t)$; a Cumulative Distribution Function $(\mathrm{CDF}), F_{T}(t)$; a Survivor Function $(\mathrm{SF}), S_{T}(t)$. The PDF is the function describing the probability that a given repose interval will exceed some time period $t$ but will not exceed $t+d t$ :

$f_{T}(t)=\lim _{d t \rightarrow 0} \frac{P(t<T \leq t+d t)}{d t}$.

The CDF, or explosion probability, is the probability that the repose interval is shorter than the time period $t$ :

$F_{T}(t)=P[T \leq t]=\int_{0}^{t} f_{T}(u) d u$.

If the CDF is continuous and differentiable, then the PDF is the derivative of the CDF. The SF is the probability of a repose interval, $T$, to exceed a time period $t$. In other words, SF describes the probability of not having an explosion during the period when $T<t$ :

$S_{T}(t)=P[T>t]=1-F_{T}(t)$,

All parametric models were fit to observed repose time datasets by maximising the appropriate likelihood function for each distribution in order to determine optimal values of the estimated coefficients. Likelihood values can be used to compare the fit of different models on the same dataset by using the negative of the log-likelihood values (better fits are related to lower values). In this study, fitting of distributions was evaluated through the maximum likelihood function (MLE) of MATLAB ${ }^{\mathrm{TM}}$ for several distribution models including exponential, Weibull, gamma, log-logistic and log-normal distributions (Cox and Oakes, 1984; Nelson, 1982). The method used to evaluate the goodness-of-fit is the Kolmogorov-Smirnov-Test (KST), based on the maximum difference between an empirical and a hypothetical cumulative distribution, evaluated at 5\% confidence levels (Nelson, 1982). 


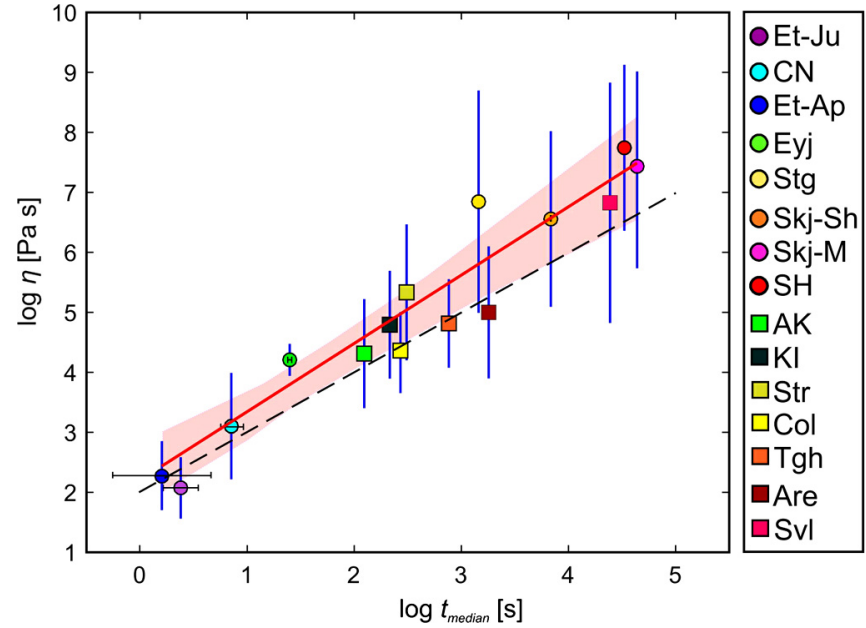

Fig. 2. Variations of magma viscosity $(\eta)$ vs. the median of the repose interval $\left(t_{\text {median }}\right)$. Error bars in X-axis correspond to the absolute error in the median and blue bars in Y-axis correspond to the range of calculated viscosities according to a minimum and maximum water content. Circles: eruptions analysed in this study, squares: published data (labels as in Table 1). Red line corresponds to the linear regression of equation (4) with the $95 \%$ confidence bounds. Dashed black line represents the simplified relation based on the equation (6).

\section{Results}

\subsection{Main characteristics of the eruptive sequences}

In most of the analysed sequences, explosions were associated with either contemporaneous lava effusion or dome growth, and vent outgassing. The explosions were classified as Strombolian, violent Strombolian and Vulcanian explosions based on semiquantitative or quantitative criteria (see Tables 1,2 and Table 1 in the ESM2 for specific references). Repose times range from $10^{-1}$ to $10^{6} \mathrm{~s}$, with median values ranging from 1.6 to $2.4 \times 10^{5} \mathrm{~s}$. Explosions formed plumes with heights ranging from a few hundred meters to $15 \mathrm{~km}$ above the vent; magma compositions range from basalt to andesite and dacite, with magma crystallinities ranging from 15 to 43 vol.\%. The data reveal that the periodicity of the explosions changes with magma compositions: mafic explosions are more frequent than explosions fed by intermediate and silicic magmas (Table 1).

The comparison between the median of observed repose time $\left(t_{\text {median }}[\mathrm{s}]\right)$ and magma viscosity $(\eta[\mathrm{Pas}])$ of pulsatory eruptions shows a strong correlation (i.e. linear in a $\log -\log$ plot, Fig. 2). This relationship can be expressed as:

$\log \eta=a \cdot \log t_{\text {median }}+b$,

where model parameters are estimated by linear regression, by taking into account the uncertainty associated with the viscosity parameter: $a=1.10 \pm 0.13\left[\frac{\log (\mathrm{Pas})}{\log (\mathrm{s})}\right]$ and $b=2.27 \pm 0.25[\log ($ Pa s $)]$, with $R^{2}=0.85$ and Pearson correlation coefficient $=0.92$.

Note that $a$ is not distinguishable from unity (1), so the equation can be written as:

$b \approx \log \left(\frac{\eta}{t_{\text {median }}}\right)$

Furthermore, based on the linear regression, letting $b=2$ :

$\eta \approx 100 \cdot t_{\text {median }}$.

This relationship is valid to one order of magnitude for magma compositions varying from $10^{2}$ to $10^{9}$ Pas and all eruptive styles analysed in this study.
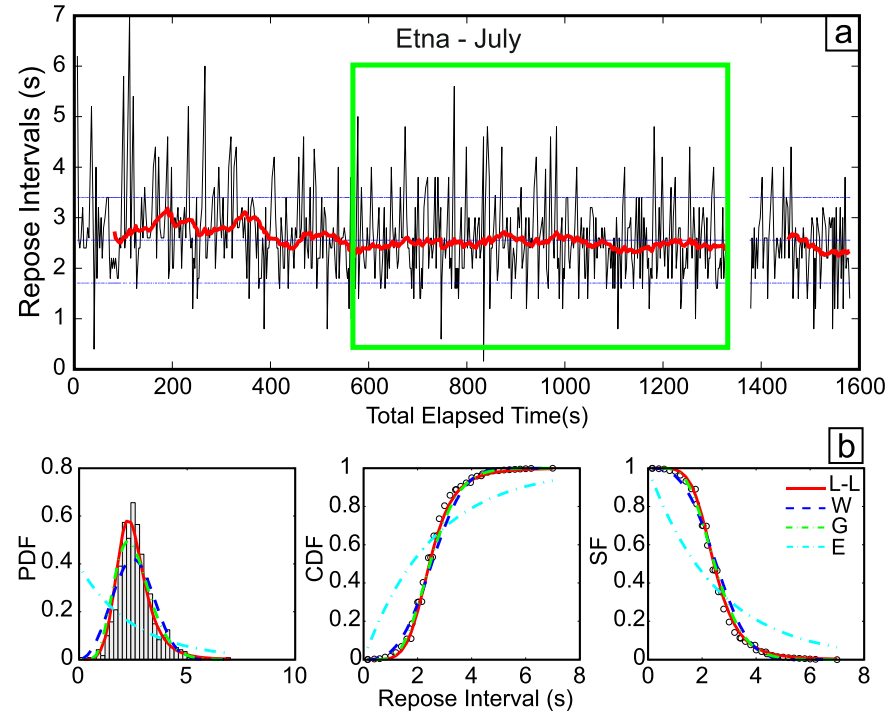

Fig. 3. (a) Etna July Time Series showing 3 main phases including the complexity linked to vent shifting. Blue lines represent the mean (middle) and mean $\pm 1 \sigma$ (upper and lower limits) and red line is the moving average test showing stationarity. Green window frame represents the selected dataset based on consecutive and stationary conditions. (b) Plot of probability functions including PDF, CDF and SF and fitted distributions for the stationary dataset. L-L: log-logistic, W: Weibull, $\mathrm{G}$ : gamma and E: exponential distributions.

\subsection{Statistical analysis}

Within each explosive sequence, a time series analysis was performed to assess stationarity and to select datasets. As an example, Fig. 3a shows the entire Etna July sequence, and the subsequent analysed dataset. Further details of the other case studies, such as the time series, analysed windows and fitted distributions, are available in the supplementary material (Figs. 1 to 7, ESM1). The main characteristics of the analysed datasets are summarised in Tables 1 and 2, including eruptive style, number of explosions and the maximum and minimum values of repose interval between explosions. Repose intervals for all the datasets are also time independent, as shown by the lack of significant peaks in the corresponding correlograms (Fig. 4). This independence in time means that these systems do not have a "memory" during a steady state eruption and, consequently, that the timing of an explosion is controlled only by the elapsed time since the previous pulse.

Considering these properties, pulsatory activity can be successfully examined as a renewal process where the system recovers after a previous explosion while the eruption dynamics does not change. Fitted distributions are graphically shown in the Fig. $3 b$ and the supplementary material (Figs. 1 to 7, ESM1). None of the datasets is well fit by an exponential distribution, rejecting the hypothesis of a homogeneous Poisson process controlling explosions, meaning that these systems are not controlled by random failure modes and constant eruption hazard rates (Wickman, 1966). Instead, most of our datasets are well described by log-logistic, log-normal, Weibull and gamma models (Table 3). Moreover, all the distributions are fitted using two independent parameters, which uniquely define each dataset. These parameters appear linearly correlated for log-normal and log-logistic distributions, suggesting that they could reflect significant information about the eruptive dynamics (correlation coefficients in the Table 3). Between these distributions, we note that the log-logistic one is the most used to describe explosive sequences (Connor et al., 2003; Varley et al., 2006; Watt et al., 2007), allowing for the direct com- 

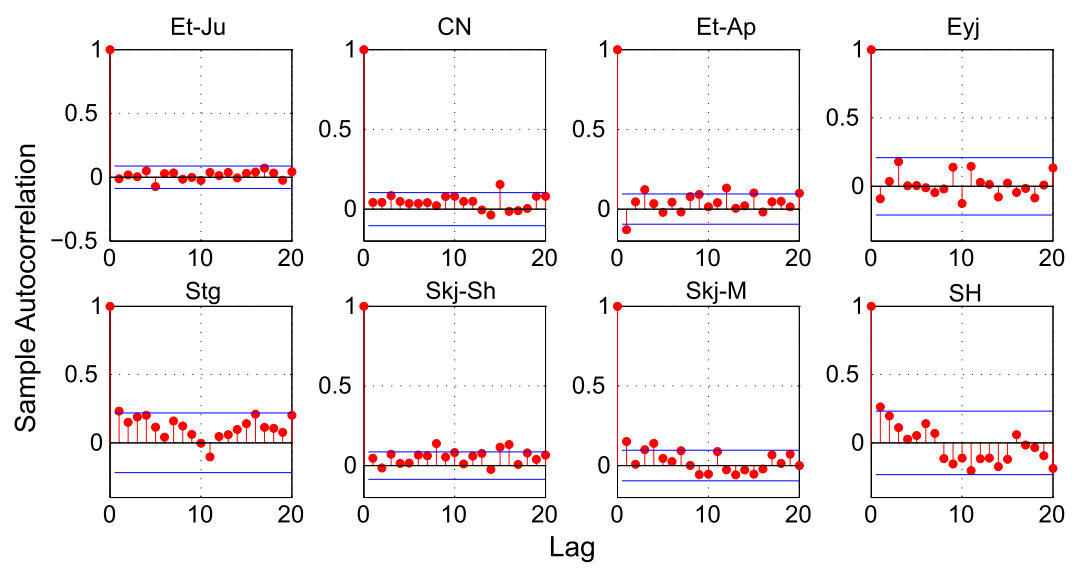

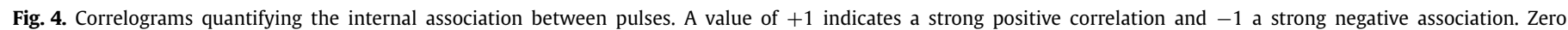
value or surrounding zero indicates no correlation. Blue lines represent the mean $\pm 2 \sigma$.

Table 3

Minimum and maximum Likelihood estimators and correlation of distribution parameters.

\begin{tabular}{|c|c|c|c|c|c|}
\hline \multirow[t]{2}{*}{ Dataset } & \multicolumn{5}{|c|}{ Negative log-likelihood values } \\
\hline & Log-logistic & Log-normal & Gamma & Weibull & $\overline{\text { Exponential }}$ \\
\hline Et-Ju & 395 & 419 & 402 & 412 & 655 \\
\hline $\mathrm{CN}$ & 977 & 988 & 971 & 975 & 1130 \\
\hline Et-Ap & 614 & 612 & 593 & 593 & 671 \\
\hline Eyj & 393 & 391 & 391 & 393 & 406 \\
\hline Stg & 716 & 718 & 713 & 713 & 719 \\
\hline Skj-Sh & 5855 & 5843 & 5894 & 5880 & 5926 \\
\hline Skj-M & 5397 & 5391 & 5407 & 5398 & 5434 \\
\hline $\mathrm{SH}$ & 813 & 815 & 815 & 821 & 848 \\
\hline \multicolumn{6}{|c|}{ Correlation coefficient of Pearson for distribution parameters } \\
\hline$R$ (p-value) & $0.66(0.076)$ & $0.62(0.101)$ & $-0.45(0.265)$ & $-0.48(0.223)$ & \\
\hline$R$ (p-value) $)^{*}$ & $0.96(0.002)$ & $0.97(0.001)$ & $-0.47(0.351)$ & $-0.59(0.216)$ & \\
\hline
\end{tabular}

${ }^{*}$ Correlation coefficient calculated excluding SH and Et-Ap datasets.

parison with previously published data. We will thus focus on the results associated with the log-logistic parameters.

\subsection{Parameters of the log-logistic distribution}

The log-logistic distribution is fitted using the parameters $\alpha$ (i.e. the median of the repose interval distribution, called scale) and $\beta$ (i.e. distribution shape). In particular, the value $t_{\text {median }}$ is the median observed, while the value of $\alpha$ is associated with the median of a statistical distribution of observed data. The derived parameters $\mu$ and $s$, which can be expressed as $\mu=\ln (\alpha)$, and $s=1 / \beta$, in analogy with the logistic distribution, better describe the frequency and variability (i.e. regularity) of each dataset (Fisk, 1961). The log-logistic PDF and CDF functions are given respectively by:

$$
\begin{aligned}
& P D F=f(t)=\frac{e^{\frac{\ln (t)-\mu}{s}}}{s\left(1+e^{\frac{\ln (t)-\mu}{s}}\right)^{2}}, \\
& C D F=F(t)=\frac{1}{1+e^{\frac{\ln (t)-\mu}{s}},}
\end{aligned}
$$

Fig. 5 shows the CDFs for the analysed datasets, while the corresponding parameters $\mu$ and $s$ are summarised in Table 4 . In general, the time scale of the distributions is controlled by the parameter $\mu$, while the shape of the distributions is strongly controlled by $s$. CDF curves show a shift from more frequent $(\mu=0.34$, Et-Ap) to less frequent explosions $(\mu=10.66$, Skj-M). The distributions corresponding to Et-Ju, CN, Et-Ap, Eyj and SH datasets are associated with lower values of $s(0.18-0.41)$ and show steepest curves; while Stg, Skj-Sh and Skj-M datasets display less steep curves and are associated with high values of $s(0.48-0.85)$. The

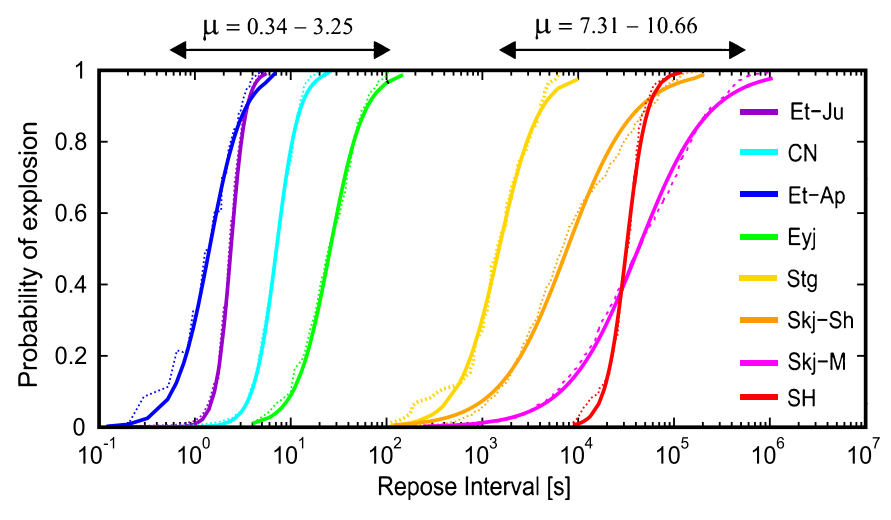

Fig. 5. Log-logistic CDFs for all the datasets exhibiting a gradual shift in the X-axis from more frequent (low $\mu$ ) to less frequent (high $\mu$ ) explosions. The variability of probability with respect to repose time reflect the variation of $s$ : rapid variation is associated with lower $s$ than gradual variation. Dashed curves correspond to the empirical CDFs.

physical meaning of $\mu$ and $s$ in terms of frequency and regularity of the process implies that systems with higher eruption frequency, such as Et-Ju, CN, Et-Ap, Eyj, are also more regular than systems with lower eruption frequency, such as Stg, Skj-Sh and Skj-M. This basic trend observed in the frequency and regularity of pulsatory activity correlates with magma properties (i.e. composition and viscosity of magmas) and conduit processes, which ultimately generate a specific eruptive style. These interactions will be explored in the next section.

Finally, we note that lava fountain activity (i.e., Et-Ap), which is characterised by very short repose times between energetic 
Table 4

Log-logistic parameters for the analysed dataset and published data. SE = Standard error. KST: KolmogorovSmirnov goodness of fit test reported as $p$-value, which is the probability of observing the test statistic as extreme as the log-logistic model. Values lower than the significance level (here, 0.05) are usually considered as rejection $(R)$ of the model. References labelled as in Table 1.

\begin{tabular}{lcllll}
\hline \multirow{2}{*}{ Dataset } & \multicolumn{2}{l}{ Log-logistic parameters } & & & \\
\cline { 2 - 6 } & $\mu[\mathrm{s}]$ & $\mu(\mathrm{SE})$ & $\mathrm{s}$ & $\mathrm{s}(\mathrm{SE})$ & $\mathrm{KST}$ \\
\hline Et-Ju & 0.87 & 0.03 & 0.18 & 0.01 & 0.06 \\
CN & 1.96 & 0.05 & 0.27 & 0.02 & 0.57 \\
Et-Ap & 0.34 & 0.07 & 0.41 & 0.03 & $\ll 0.05$ \\
Eyj & 3.25 & 0.15 & 0.41 & 0.06 & 0.58 \\
Stg & 7.31 & 0.18 & 0.48 & 0.08 & 0.96 \\
Skj-Sh & 8.95 & 0.12 & 0.81 & 0.05 & 0.05 \\
Skj-M & 10.66 & 0.14 & 0.85 & 0.06 & 0.28 \\
SH & 10.37 & 0.10 & 0.25 & 0.04 & 0.84 \\
Published data (Ref.) & & & & & \\
Tgh (2004) (8) & 6.64 & - & & & 0.79 \\
Col (May 2002) (8) & 5.73 & - & 0.62 & - & - \\
AK (12-13 Jan 1960) (10) & 4.82 & - & 0.39 & - & 0.31 \\
KI (22-23 Feb 1926) (10) & 5.37 & - & 0.53 & - & 0.44 \\
Svl (4 Jan 2002-30 Nov 2003) (11) & 10.10 & - & 0.83 & - & - \\
\hline
\end{tabular}

KST: Kolmogorov Smirnov test reported by Varley et al. (2006) as test statistic (significance level).

magma jets, likely represents a transition towards steady state activity, with the duration of pulses approaching their repose times. Given that the log-logistic goodness-of-fit is poor, as evidenced in the low p-value of the KST (Table 4), this dataset will be disregarded from further analysis.

\section{Discussion}

Pulsatory eruptions are fed by magma of almost any composition (and viscosity) showing a large variability of explosion intensity, frequency and duration. In all the analysed cases, contemporaneous lava dome or lava flow activity and inter-explosive vent outgassing suggest that separated two-phase flow regimes in the conduit (i.e. the uncoupled-rise of gas and magma) characterise the discontinuous explosive style. In pulsatory events, the frequency of explosions reflects the timescale of the repose interval and it is expected to be a direct function of fragmentation processes, which are in turn affected by magma degassing, permeability development, overpressure and shearing effects (Cashman, 2004; Mueller et al., 2008). Magma viscosity controls not only fragmentation mechanisms (i.e. inertially-driven to fragile) but also flow dynamics in the conduit, including flow regimes and their transitions (Papale, 1999; Gonnermann and Manga, 2012; Pioli et al., 2012), suggesting that the analysed explosive sequences are characterised by distinct conduit flow and fragmentation dynamics. For example, the separated flow dynamics in low-viscosity systems is controlled by bubble rise (Vergniolle and Jaupart, 1986; Pioli et al., 2012), whereas in high-viscosity systems it develops as permeable, fracture-controlled flow (Diller et al., 2006). However, in both cases the explosive regimes result in periodical shifting of flow properties, which ultimately control fragmentation dynamics. The empirical relationship between magma viscosity and median of the repose time (eq. (4)) suggests that viscosity is the main magma property which ultimately controls the frequency of explosions in open vent systems. This empirical relationship applies regardless of the distribution model used, eruption length, eruptive style and associated plume heights, with no significant shift or discontinuity, and is valid for viscosities ranging from $10^{2}$ to $10^{9} \mathrm{~Pa} \mathrm{~s}$, being representative of almost the entire range of magma compositions. This result implies that, at stationary conditions, $i$ ) variations in the median explosion frequency reflect main changes in the magma viscosity (i.e. crystallinity, volatile content or composition) and ii) these variations occur across distinct flow regimes and fragmentation dynamics. We note that conduit flow regimes could be potentially discriminated by taking into account further eruptive parameters (i.e. mass erupted, MER or outgassing dynamics, Green et al., 2013). Unfortunately, these are rarely available for single explosive pulses, preventing eruption comparison.

Survival analysis of selected representative eruptions gives additional information on the temporal distribution of explosions (i.e. the type and shape of the distributions of repose times). The timing of explosive events results from a combination of several processes acting in the conduit, which ultimately favour, or inhibit, magma fragmentation and explosion. The properties of the distributions show regular variations in shape and time-scale reflected by a continuous variation of the statistical log-logistic parameters $\mu$ and $s$ (Fig. 5), resulting in a strong positive correlation between both parameters, as evidenced in Fig. 6. This is a robust correlation that matches with the qualitative classification of eruptive styles based on observations (Table 1), and confirms a continuous variation of characteristics passing from more frequent and regular Strombolian and violent Strombolian eruptions to less frequent and irregular Vulcanian eruptions.

A clear outlier to this trend is the SH dataset, which shows lower value of $s$ (i.e. more regular eruptions) with respect to similar style eruptions, such as Skj-Sh and Skj-M datasets. Such regular periodicity in SH dataset could be induced by deeper processes where frequency is strictly controlled by magma supply rate, plug formation, over-pressure build-up and resulting stick-slip cycles (Denlinger and Hoblitt, 1999; Jaquet et al., 2006). Furthermore, we notice that $\mathrm{SH}$ explosive sequence was characterised by larger erupted mass per explosion (i.e. average of $10^{8} \mathrm{~kg}$ of erupted mass per explosion; Druitt et al., 2002) with respect to the other sequences analysed in this study. Therefore, excluding SH dataset, the correlation coefficient $(R)$ of parameters, $\mu$ and $s$, for all the studied datasets and the published explosions, reaches 0.93 .

The $\log \operatorname{logistic}$ parameter $\mu$ is a function of $\alpha$, the median of the fitted distribution, which, for the analysed dataset, equals the median of observed repose time $\left(t_{\text {median }}\right)$ with a maximum percentage difference of $12 \%$. For this reason, we can assume that, the relationship of magma viscosity of eq. (4) can also be applied to the median of the distribution $(\alpha)$ as shown in the Fig. 6 . The regularity of the explosive pulses (indirectly quantified by the parameter $s$ ) reflects the interplay among several processes, each acting at different timescales and contributing to the complexity of each system within a stationary regime. The time to an explosion might be due to a combination of dependent variables (e.g. porosity development, magma feeding rate) rather than a single 


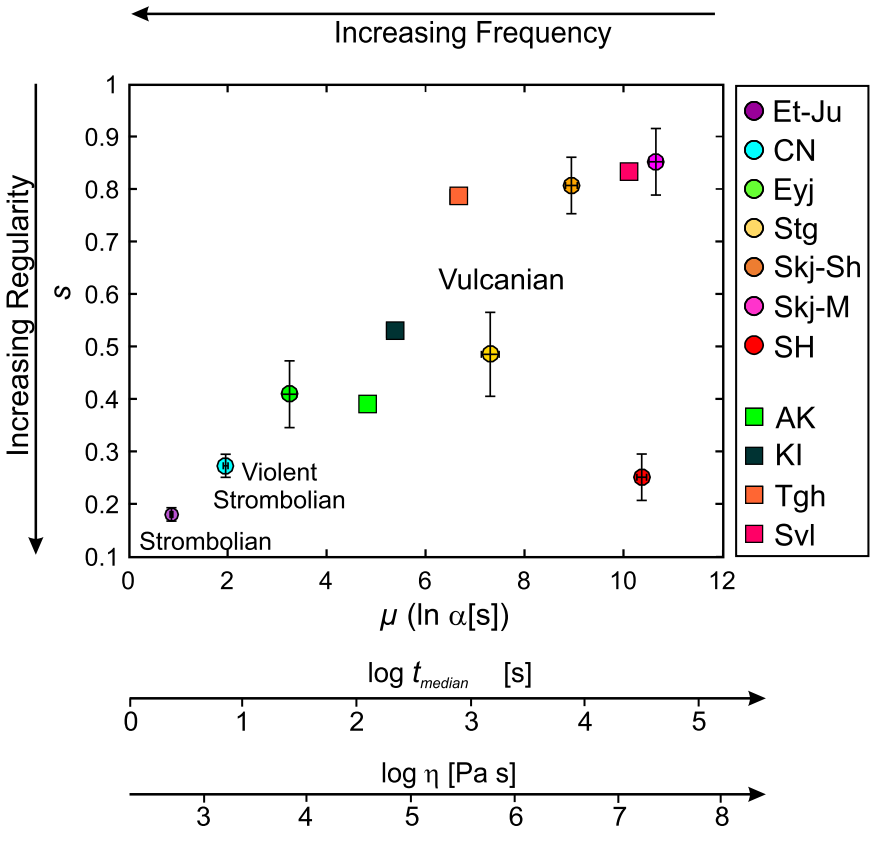

Fig. 6. Variation of log-logistic parameters, $\mu$ and $s$, for the analysed datasets (circles) and previously studied eruptions (squares). Labels as in Table 1. Error bars correspond to the standard error of fitted parameters. Correlation among $\mu, \alpha, t_{\text {median }}$ and viscosity is based on equation (4). The difference between $t_{\text {median }}$ and $\alpha$ (the median of the fitted distribution) ranges from $1 \%$ (Et-Ju) to $12 \%$ (Skj-Sh).

failure process, the fragmentation itself. Therefore, the regularity of the distribution is positively correlated to the complexity of the system, i.e. the number of variables (processes) involved and the range of associated timescales, which are derived from the balance between magma-rise rate and fragmentation efficiency. The positive correlation between $\mu$ and $s$ suggests that for low-frequency explosions, the regularity of the system decreases, implying that $i$ ) the number of physical processes controlling the activity increases, or $i i)$ the interaction among variables has stronger non-linear effects.

Survival analysis and log-logistic fitting allows for the characterisation of the average properties of Strombolian sequences (low $s$, low $\mu$ ) with respect to Vulcanian sequences (higher $s$ and $\mu$ ), but they also show that the periodicity of explosion (i.e. the distribution of the repose times) varies regularly across the eruptive styles and therefore the definition of a threshold between the eruptive styles (i.e. critical $\mu$ and $s$ ) is ambiguous. In other words, it is very difficult to define limits of Strombolian and Vulcanian styles based only on the distribution of repose intervals, because the distribution of eruptive pulses changes regularly across degassing (i.e. bubble vs. fracture controlled), and fragmentation regimes (i.e. inertially driven vs. fragile), which characterise the different styles. Classification of different styles of pulsatory explosive activity is, thus, a complex task, which requires the definition of several criteria based not only on tephra characteristics and column height, but also on the analysis of the pulsatory behaviour. This is one of the main reasons of confusion and uncertainty related to the application of traditional classification schemes.

\section{Concluding remarks}

Volcanoes are complex stochastic systems within which several physical processes, characterised by distinct timescales, interact. In the case of eruptions consisting of sequences of explosions, i.e. pulsatory explosive activity, the distribution of repose time between explosions gives important information on the eruption dynamics.
In our datasets, repose times show positively skewed distributions, which can be satisfactorily fitted by several univariate models. In any case, the median of the repose times $\left(t_{\text {median }}\right)$ is positively correlated with the viscosity of the magma, and to one order of magnitude follows the simple relationship $\eta \approx 100 \cdot t_{\text {median }}$, suggesting that viscosity is the main magma property controlling eruption periodicity.

A more detailed analysis of the selected type style sequences allowed for the direct comparison of eruptions marked by different styles and intensities. Accordingly, survival analysis of the repose interval between consecutive explosions provides insights not only into quantifying unsteadiness but also into understanding key mechanisms of explosion dynamics. Among several models which could be used to describe these distributions, the log-logistic one is the most suitable because it describes accurately all the eruptions and is capable to depict the regular variations of the properties of distributions of Strombolian to Vulcanian eruptions by means of the key parameters, $\mu$ and $s$, which are linearly related.

While $\mu$ is a function of the median of repose time and can be correlated with magma viscosity, the log-logistic parameter $s$, quantifying the regularity of explosions, is a function of the system complexity and represents the response to the interaction of several processes and parameters (e.g. magma feeding rate, porosity, permeability, conduit and plumbing system geometry). The relation between $\mu$ and $s$ encompasses the interplay between magma viscosity and conduit processes, which in turn controls fragmentation dynamics, showing a continuous variation between eruptive styles from very frequent and regular mafic events (Strombolian and violent Strombolian) to more sporadic Vulcanian behaviour at silicic systems. These results suggest that, due to the complexity of their dynamics, classification of pulsatory eruption should be based not only on the properties of the tephra deposit and plume height, but also on the periodicity of the pulses.

Finally, we note that survival analysis of explosive pulses is a relatively simple method, which enables the quantification of the pulsatory behaviour of volcanoes during ongoing eruptions. In addition, due to the strong correlation between the distribution parameters and magma viscosity, it also has enormous potential for probabilistic hazard assessment and eruption forecasting.

\section{Acknowledgements}

We are grateful to A. Yokoo and M. Ichihara for providing data of Sakurajima datasets. Cerro Negro video was collected by B. Hill, M. Conway and P. La Femina. We are grateful to G. Simpson, L. Caricchi and M. Bebbington for their insightful comments on a previous version of this manuscript. Thanks to T. Mather, D. Pyle and an anonymous reviewer for constructive comments. This work was partially supported by an Augustin Lombard grant from the SPHN Society of Geneva.

\section{Appendix A. Supplementary material}

Supplementary material related to this article can be found online at http://dx.doi.org/10.1016/j.epsl.2016.03.048.

\section{References}

Andronico, D., Scollo, S., Cristaldi, A., Lo Castro, M.D., 2014. Representivity of incompletely sampled fall deposits in estimating eruption source parameters: a test using the 12-13 January 2011 lava fountain deposit from Mt. Etna volcano, Italy. Bull. Volcanol. 76, 861. http://dx.doi.org/10.1007/s00445-014-0861-3.

Bonadonna, C., Cioni, R., Costa, A., Druitt, T., Phillips, J., Pioli, L., 2014. Dynamics of volcanic explosive eruptions. Consensual document of the MeMoVolc workshop. https://vhub.org/resources/3561.

Cashman, K.V., 2004. Volatile controls on magma ascent and eruption. In: The State of the Planet: Frontiers and Challenges in Geophysics. In: American Geophysical Union Monograph, vol. 150, pp. 109-124. 
Chojnicki, K.N., Clarke, A.B., Phillips, J.C., Adrian, R.J., 2015. Rise dynamics of unsteady laboratory jets with implications for volcanic plumes. Earth Planet. Sci. Lett. 412, 186-196. http://dx.doi.org/10.1016/j.epsl.2014.11.046.

Ciancitto, F., Sciotto, M., Spina, L., Lodato, L., Privitera, E., Andronico, D., 2012. The 2012 explosive activity at Bocca Nuova (Mt. Etna): preliminary correlation between thermal data and acoustic signal. In: Riassunti estesi Conferenza A. Rittmann. Nicolosi, Catania, 12-14 Dicembre 2012, pp. 55-56. Miscellanea INGV, 15, ISSN 2039-6651.

Connor, C.B., Sparks, R.S.J., Mason, R.M., Bonadonna, C., Young, S.R., 2003. Exploring links between physical and probabilistic models of volcanic eruptions: the Soufrière Hills volcano, Montserrat. Geophys. Res. Lett. 30 (13), 1701. http:// dx.doi.org/10.1029/2003GL017384.

Costa, A., Caricchi, L., Bagdassarov, N., 2009. A model of the rheology of particlebearing suspensions and partially molten rocks. Geochem. Geophys. Geosyst. 10, Q03010.

Cox, D.R., Oakes, D., 1984. Analysis of Survival Data. Chapman and Hall, London. $208 \mathrm{p}$.

Cox, D.R., Lewis, P.A.W., 1966. The Statistical Analysis of Series Events. 285 pp.

Denlinger, R.P., Hoblitt, R.P., 1999. Cyclic eruptive behaviour of silicic volcanoes. Geology 27, 459-462.

Diller, K., Clarke, A.B., Voight, B., Neri, A., 2006. Mechanisms of conduit plug formation: implications for vulcanian explosions. J. Geophys. Res. 33. http:// dx.doi.org/10.1029/2006GL027391.

Dirksen, O., Humphreys, M.C.S., Pletchov, P., Melnik, O., Demyanchuk, Y., Sparks, R.S.J., Mahony, S., 2006. The 2001-2004 dome-forming eruption of Shiveluch volcano, Kamchatka: observation, petrological investigation and numerical modelling. J. Volcanol. Geotherm. Res. 155 (3-4), 201-226. http:// dx.doi.org/10.1016/j.jvolgeores.2006.03.029.

Druitt, T.H., Young, S.R., Baptie, B., Bonadonna, C., Calder, E.S., Clarke, A.B., Cole, P.D., Harford, C.L., Herd, R.A., Luckett, R., Ryan, G., Voight, B., 2002. Episodes of cyclic vulcanian explosive activity with fountain collapse at Soufrière Hills Volcano, Montserrat. Mem. Geol. Soc. Lond. 21 (1), 281-306. http://dx.doi.org/10.1016/ S1631-0713(02)01742-X.

Dzierma, Y., Wehrmann, H., 2010. Eruption time series statistically examined: probabilities of future eruptions at Villarica and Llaima volcanoes, Southern volcanic zone, Chile. J. Volcanol. Geotherm. Res. 193 (1-2), 82-92. http:// dx.doi.org/10.1016/j.jvolgeores.2010.03.009.

Fisk, P., 1961. The graduation of income distributions. Econometrica 29 (2), 171-185.

Giordano, D., Russell, J.K., Dingwell, D.B., 2008. Viscosity of magmatic liquids: a model. Earth Planet. Sci. Lett. 271 (1-4), 123-134. http://dx.doi.org/10.1016/ j.epsl.2008.03.038.

Gonnermann, H.M., Manga, M., 2012. Dynamics of magma ascent in the volcanic conduit: modeling volcanic processes. In: The Physics and Mathematics of Volcanism. Cambridge University Press, pp. 55-84.

Green, R.M., Bebbington, M.S., Cronin, S.J., Jones, G., 2013. Geochemical precursors for eruption repose length. Geophys. J. Int. 193, 855-873.

Gudmundsson, M.T., Thordarson, T., Hoskuldsson, A., Larsen, G., Bjornsson, H., Prata, F.J., Oddsson, B., Magnusson, E., Hognadottir, T., Petersen, G., Hayward, C.L., Stevenson, J., Jonsdottir, I., 2012. Ash generation and distribution from the AprilMay 2010 eruption of Eyjafjallajokull, Iceland. Sci. Rep. 2, 572.

Harris, A.J.L., Rose, W.I., Flynn, L.P., 2003. Temporal trends in lava dome extrusion at Santiaguito 1922-2000. Bull. Volcanol. 65, 77-89.

Hill, B.E., Connor, C., Jarzemba, M., La Femina, P.C., Navarro, S., Strauch, W., 1998. 1995 eruptions of Cerro Negro volcano, Nicaragua, and risk assessment for future eruptions. Geol. Soc. Am. Bull. 110 (10), 1231-1241.

Iguchi, M., 2013. Characteristics of Volcanic activity at Sakurajima volcano's show a crater during the period 2006 to 2011. Bull. Volcanol. Soc. Jpn. 58 (1), 115-135.

INGV, Bollettino settimanale sul monitoraggio vulcanico, geochimico e sismico del vulcano Etna $N^{\circ}$ 16, Istituto Nazionale di Geofisica e Vulcanologia (2012).

Jaquet, O., Sparks, R.S.J., Carniel, R., 2006. Magma memory recorded by statistics of volcanic explosions at the Soufrière Hills volcano, Montserrat. In: Statistics in Volcanology, pp. 175-184. Chapter 14.

MacDonald, G.A., 1972. Volcanoes. A Discussion of Volcanoes, Volcanic Products, and Volcanic Phenomena. Prentice-Hall, New Jersey.

Marchetti, E., Ripepe, M., Harris, A., Delle Donne, D., 2009. Tracing the differences between Vulcanian and Strombolian explosions using infrasonic and thermal radiation energy. Earth Planet. Sci. Lett. 279, 273-281. http://dx.doi.org/ 10.1016/j.epsl.2009.01.004.
Marzocchi, W., Bebbington, M.S., 2012. Probabilistic eruption forecasting at short and long time scales. Bull. Volcanol. 74, 1777-1805. http://dx.doi.org/10.1007/ s00445-012-0633-X.

Mason, R.M., Starostin, A.B., Melnik, O.E., Sparks, R.S.J., 2006. From Vulcanian explosions to sustained explosive eruptions: the role of diffusive mass transfer in conduit flow dynamics. J. Volcanol. Geotherm. Res. 153, 148-165. http://dx.doi.org/10.1016/j.jvolgeores.2005.08.011.

Moitra, P., Gonnermann, H., Houghton, B.F., Giachetti, T., 2013. Relating vesicle shapes in pyroclasts to eruption styles. Bull. Volcanol. 75, 691. http://dx.doi.org/ 10.1007/s00445-013-0691-8.

Mueller, S., Scheu, B., Spieler, O., Dingwell, D.B., 2008. Permeability contro on magma fragmentation. Geology 36 (5), 399. http://dx.doi.org/10.1130/ G24605A.1.

Nelson, W., 1982. Applied Life Data Analysis. John Wiley \& Sons, New York.

Papale, P., 1999. Strain-induced magma fragmentation in explosive eruptions. Nature 397, 425-428. http://dx.doi.org/10.1038/17109.

Pioli, L., Bonadonna, C., Azzopardi, B.J., Phillips, J., Ripepe, M., 2012. Experimental constraints on the outgassing dynamics of basaltic magmas. J. Geophys. Res. 117 B03204. http://dx.doi.org/10.1029/2011JB008392.

Pyle, D., 1989. The thickness, volume and grainsize of tephra fall deposits. Bull. Volcanol. 51, 1-15.

Pyle, D., 1998. Forecasting sizes and repose times of future extreme volcanic events. Geology 26, 367-370.

Ripepe, M., Delle Donne, D., Harris, A., Marchetti, E., Ulivieri, G., 2008. Dynamics of Stromboli Volcano: An Integrated Study of the 2002-2003 Eruption. Geophys. Monograph Series, vol. 182. Am. Geophys. Union.

Ripepe, M., Bonadonna, C., Folch, A., Delle Donne, D., Lacanna, G., Marchetti, E., Hoskuldsson, A., 2013. Ash-plume dynamics and eruption source parameters by infrasound and thermal imagery: the 2010 Eyjafjallajökull eruption. Earth Planet. Sci. Lett. 366, 112-121. http://dx.doi.org/10.1016/j.epsl.2013.02.005.

Roggensack, K., Hervig, R., McKnight, S., Williams, S., 1997. Explosive basaltic volcanism from Cerro Negro volcano: influence of volatiles on eruptive style. Science 277 (April 1992), 1639-1642.

Rose, W.I., 1972. Santiaguito volcanic dome, Guatemala. Geol. Soc. Am. Bull. 83 (5) 1414-1434

Ruiz, M., Lees, J., Johnson, J., 2005. Source constrains of Tungurahua volcano explosion events. Bull. Volcanol. 68 (5), 480-490. http://dx.doi.org/10.1007/ s00445-005-0023-8.

Sahetapy-Engel, S.T., Harris, A.J.L., Marchetti, E., 2008. Thermal, seismic and infrasound observations of persistent explosive activity and conduit dynamics at Santiaguito lava dome, Guatemala. J. Volcanol. Geotherm. Res. 173 (1-2), 1-14. http://dx.doi.org/10.1016/j.jvolgeores.2007.11.026.

Spilliaert, N., Allard, P., Métrich, N., Sobolev, A.V., 2006. Melt inclusion record of the conditions of ascent, degassing, and extrusion of volatile-rich alkali basalt during the powerful 2002 flank eruption of mount Etna (Italy). J. Geophys. Res. 111, B04203. http://dx.doi.org/10.1029/2005JB003934.

Valade, S., Donnadieu, F., Lesage, P., Mora, M.M., Harris, A., Alvarado, G.E., 2012. Explosion mechanisms at Arenal volcano, Costa Rica: an interpretation from integration of seismic and Doppler radar data. J. Geophys. Res. 117 (B1) http://dx.doi.org/10.1029/2011JB008623.

Valentine, G., Gregg, T., 2008. Continental basaltic volcanoes - processes and problems. J. Volcanol. Geotherm. Res. 177 (4), 857-873. http://dx.doi.org/10.1016/ j.jvolgeores.2008.01.050.

Varley, N., Kalbfleisch, J. son, Ruiz, M., Reyes, G., Martin, K., 2006. Applying statistical analysis to understanding the dynamics of volcanic explosions. In: Statistics in Volcanology, pp. 57-76. Chapter 6.

Vergniolle, S., Jaupart, C., 1986. Separated two-phase flow and basaltic eruptions. J. Geophys. Res. 91 (B12), 12842-12860. http://dx.doi.org/10.1029/ JB091iB12p12842.

Voight, B., 1988. A method for prediction of volcanic eruptions. Nature 332 125-130.

Walker, G.P.L., 1973. Explosive volcanic eruptions - a new classification scheme. Geol. Rundsch. 62, 431-446.

Watt, S.F.L., Mather, T.A., Pyle, D.M., 2007. Vulcanian explosions cycles: patterns and predictability. Geology 35 (9), 839-842. http://dx.doi.org/10.1130/G23562A.1.

Webb, E., Varley, N., Pyle, D., Mather, T., 2014. Thermal imaging and analysis of short-lived vulcanian explosions at Volcan de Colima, Mexico. J. Volc. Geotherm. Res. 278-279, 1332-1345. http://dx.doi.org/10.1016/j.jvolgeores.2014.03.013.

Wickman, F.E., 1966. Repose-period patterns of volcanoes. Ark. Mineral. Geol. 4, 291-367. 